\title{
NBSIR $87-3557$
}

\section{An Analysis of the Pressure Rise in Sealed Magazine Fires}

Howard R. Baum

\author{
U.S. DEPARTMENT OF COMMERCE \\ National Bureau of Standards \\ National Engineering Laboratory \\ Center for Fire Research \\ Gaithersburg, MD 20899
}

November 1987

$\begin{array}{ll}-Q C & \text { part by: } \\ 100 & \text { apons Center } \\ . \cup 56 & \text { re, California }\end{array}$

$87-3557$

1987

C. 2 



\section{NBSC \\ QC100 \\ . 456 \\ mo. $87-3557$ \\ 1987 \\ c. 2}

Howard R. Baum

U.S. DEPARTMENT OF COMMERCE

National Bureau of Standards

National Engineering Laboratory

Center for Fire Research

Gaithersburg, MD 20899

November 1987

Supported in part by:

Navy Weapons Center

China Lake, California

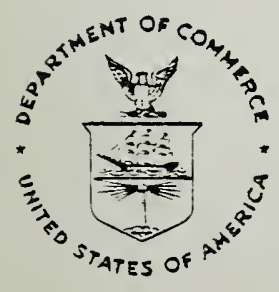

U.S. DEPARTMENT OF COMMERCE, C. William Verity, Acting Secretary NATIONAL BUREAU OF STANDARDS. Ernest Ambler, Director 

Page

List of Figures $\ldots \ldots \ldots \ldots \ldots \ldots \ldots \ldots \ldots \ldots \ldots \ldots \ldots \ldots \ldots \ldots \ldots \ldots \ldots \ldots$ iv

Abstract $\ldots \ldots \ldots \ldots \ldots \ldots \ldots \ldots \ldots \ldots \ldots \ldots \ldots \ldots \ldots \ldots \ldots \ldots \ldots \ldots \ldots \ldots \ldots \ldots \ldots$

1. INTRODUCTION $\ldots \ldots \ldots \ldots \ldots \ldots \ldots \ldots \ldots \ldots \ldots \ldots \ldots \ldots \ldots \ldots \ldots \ldots \ldots \ldots \ldots$

2. MATHEMATICAL MODEL ............................. 2

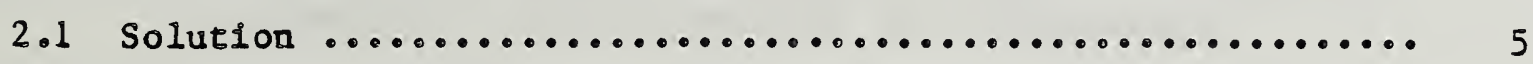

3. RESULTS AND DISCUSSION ........................... 8

4. ACKNOWLEDGMENTS $\ldots \ldots \ldots \ldots \ldots \ldots \ldots \ldots \ldots \ldots \ldots \ldots \ldots \ldots \ldots \ldots \ldots \ldots \ldots \ldots \ldots$

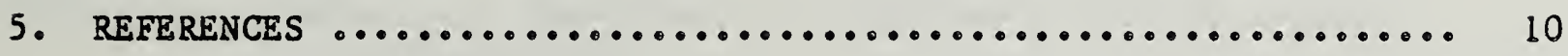




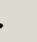


Figure 1a. Dimensionless layer height $\mathrm{Z} / \mathrm{H}$ as function of time in seconds for configuration $1 . x$ is the fraction of the chemical heat release lost from the gas by radiation ....... 12

Figure $1 \mathrm{~b}$. Pressure in atmospheres as function of time in seconds for configuration 1 ................................ 13

Figure lc. Ratio of upper layer temperature to ambient temperature as function of time in seconds for configuration 1 ........ 14

Figure 2a. Dimensionless layer height $\mathrm{Z} / \mathrm{H}$ as function of time in seconds for configuration 2. $x$ is the fraction of the chemical heat release lost from the gas by radiation ........ 15

Figure $2 \mathrm{~b}$. Pressure in atmospheres as function of time in seconds

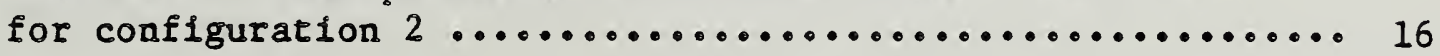

Figure 2c. Ratio of upper layer temperature to amblent temperature as function of time in seconds for configuration $2 \ldots \ldots \ldots . .17$

Figure 3a. Dimensionless layer height $\mathrm{Z} / \mathrm{H}$ as function of time in seconds for configuration 3 . $x$ is the fraction of the chemical heat release lost from the gas by radiation ........ 18

Figure $3 \mathrm{~b}$. Pressure in atmospheres as function of time in seconds for configuration $3 \ldots \ldots \ldots \ldots \ldots \ldots \ldots \ldots \ldots \ldots \ldots \ldots . \ldots \ldots$

Figure $3 c$. Ratio of upper layer temperature to ambient temperature as function of time in seconds for configuration $3 \ldots \ldots \ldots .20$

Figure 4a. Dimensionless layer height $\mathrm{Z} / \mathrm{H}$ as function of time in seconds for configuration $4 . x$ is the fraction of the chemical heat release lost from the gas by radiation ........ 21

Figure $4 \mathrm{~b}$. Pressure in atmospheres as function of time in seconds for configuration $4 \ldots \ldots \ldots \ldots \ldots \ldots \ldots \ldots \ldots \ldots \ldots \ldots \ldots \ldots . \ldots \ldots$

Figure 4c. Ratio of upper layer temperature to ambient temperature as function of time in seconds for configuration $4 \ldots \ldots \ldots .23$ 


$$
\text { - }
$$


AN ANALYSIS OF THE PRESSURE RISE IN SEALED MAGAZINE FIRES

Howard R. Baum

Abstract

A thematical model for the pressure and temperature rise in sealed ship magazines caused by propellant fires is developed. The model is a simplified version of several existing zone fire models, modified to consider sealed compartments. The equations describing the model are solved exactly. Sample results are shown for a variety of magazine geometries.

\section{INTRODUCTION}

A propellant fire in a sealed magaine possesses two features not present in most building compartment fires. First, the propellant contains its own oxidizer, permitting the fire to be maintained even in the absence of an adequate supply of room air. Second, the magazine is sealed with a structure designed to resist large pressure differences between the internal and external environments. As a result, a large pressure rise can occur in a magazine fire, unlike most building compartment fires. Although adequate computer models for closed bullding compartments [1], as well as more general building environments $[2,3]$ exist, their tacit assumption of a limited pressure rise prevents their. use for the present investigation. However, in most respects, the mathematical model presented below is really nothing more than a greatly simplified version of what is already implemented in these codes. The additional simplifying assumptions permt exact analytical solutions to be obtained for the pressure and temperature histories in the magas zine. These solutions permit the sensitivity of the results to the various 
thermophysical and geometric parameters which describe the problem to be readily assessed. They should be of some interest in their own right as there are few, if any, other exact solutions to the compartment fire equations.

\section{MATHEMATICAL MODEL}

The magazine is assumed to be a closed rectangular volume of height $H$ and plan area A. The propellant fire is represented by a source of heat of constant strength Q. At any instant of time $t$ the flow pattern consists of a buoyant plume feeding heat and mass into a uniformly mixed hot upper layer of temperature $T(t)$. Beneath the hot upper layer is a cold layer of gas assumed to be at the ambient temperature $T_{0}$. The plume entrains mass from the lower layer causing the interface height $Z(t)$ to descend towards the floor. The pressure $P(t)$ is the same everywhere in the magazine at each instant of time. The theoretical and experimental justification for this picture is analyzed by Quintiere [4].

In order to predict the evolution of the mean pressure, temperature, and interface height with time, it is necessary to consider mass and energy balances in the enclosure. Let $\rho_{u}$ and $\rho_{L}$ be the gas densities in the upper and lower layers, respectively. Then, using the perfect gas equation of state, these quantities can be rewritten as:

$$
\rho_{u}=\frac{P(t)}{R T(t)} ; \rho_{L}=\frac{P(t)}{R T{ }_{0}}
$$

Here $\mathrm{R}$ is the gas constant. Since the room is sealed, and the propellant mass is much smaller than the room air mass, the total mass of gas in the room can 
be taken as constant. Thus, if $P_{0}$ is the initial ambient pressure:

$$
P\left\{\frac{(H-Z)}{T}+\frac{Z}{T_{0}}\right\}=\frac{P_{0} H}{T_{0}}
$$

Next consider the mass flow into the upper layer. If $\stackrel{m}{(2}(Z)$ is the mass flux entrained into the buoyant plume at a height $Z$ above the source, then a mass balance in the upper layer yields

$$
\frac{\mathrm{d}}{\mathrm{dt}}\left\{\frac{\mathrm{AP}}{\mathrm{RT}}(\mathrm{H}-\mathrm{Z})\right\}=\dot{\mathrm{m}}(\mathrm{Z}) \text {. }
$$

Cetegen, et al. [5] proposed a simple empirical formula for $\dot{m}$ based on a comparison of the point source plume theory with a variety of experimental data. In the present notation:

$$
\dot{\mathrm{m}}(z)=0.21 \rho_{L} \sqrt{g Z} z^{2}\left\{Q / \rho_{L} C_{P} T_{0} \sqrt{g Z} z^{2}\right\}^{1 / 3}
$$

Here, $g$ is the gravitational acceleration and $C_{p}$ the specific heat at constant pressure.

Finally, consider an energy balance for the entire magazine. The internal energy per unit volume is $P(t) /(\gamma-1)$, where $\gamma$ is the specific heat ratio in the gas. Since the chamber is sealed with immovable walls, the first law of thermodynamics can be written for the whole enclosure in the form:

$$
\frac{d}{d t}\left\{\frac{\operatorname{AHP}(t)}{(\gamma-1)}\right\}=(1-x) Q-q_{c} A
$$


The first term on the right hand side of eq. (5) is the rate at which heat is released into the magazine. A fraction $x$ of the total chemical heat release rate $Q$ is radiated out of the gas. The second term represents the convective heat lost to the ceiling and walls in the upper layer. The quantity $q_{c}$ is the convective heat flux per unit area, and it is assumed to be related to the temperature rise above the ambient ceiling temperature by a heat transfer coefficient $\mathrm{h}$ as follows:

$$
q_{c}=h\left(T(t)-T_{0}\right)
$$

Equations (1)-(6) constitute the mathematical system to be solved. It must be supplemented by initial conditions for the interface height $Z(t)$ and pressure $P(t)$. The natural choice is

$$
\begin{aligned}
& Z(0)=H \\
& P(0)=P_{0}
\end{aligned}
$$

The initial temperature cannot be specified but must be determined as part of the solution. This situation arises because a steady-state plume model is used in the analysis which delivers hot gas to the ceiling in zero time. Mathematically, the system is equivalent to a second order system of differential equations, which can only support two initial conditions. 


\subsection{Solution}

Using eq. (2) to eliminate the temperature, the mathematical problem can be reduced to the solution of the following pair of differential equations for $P(t)$ and $Z(t)$.

$$
\begin{aligned}
& \frac{1}{\gamma-1} \frac{d P}{d t}+\frac{h T_{0}\left(P-P_{0}\right)}{P_{0} H-P Z}=\frac{Q_{0}(1-x)}{A H} \\
& \frac{d}{d t}(P Z)=-\frac{0.21}{A} \text { gQ } \frac{\gamma-1}{\gamma} 1 / 3(P Z)^{2 / 3} Z
\end{aligned}
$$

Now introduce non-dimensional variables $\hat{P}(\tau)$ and $\hat{Z}(\tau)$ in the form

$$
\begin{aligned}
& P=P_{O} \hat{P}(\tau) \\
& Z=H \hat{Z}(\tau) \\
& t={\frac{P}{g Q H^{2}}}^{1 / 3} A \tau .
\end{aligned}
$$

Equations ( 7 ) and ( 8 ) then can be rewritten as:

$$
\begin{aligned}
& \frac{d \hat{P}}{d \tau}+\Delta \frac{(\hat{P}-1)}{(1-\hat{P} \hat{Z})}=q \\
& \frac{d}{d \tau}(\hat{P} \hat{Z})=-\alpha(\hat{Z} \hat{P})^{5 / 3} / \hat{P} \\
& \alpha=0.21 \frac{Y-1}{\gamma} 1 / 3 \\
& \Delta=\frac{(\gamma-1) h_{0} A}{H\left(g Q H^{2} \mathrm{p}_{0}^{2}\right)^{1 / 3}}
\end{aligned}
$$




$$
\begin{aligned}
& q=(1-x) \frac{(\gamma-1)}{H}{\frac{Q}{\sqrt{g} P_{0} H}}^{2 / 3} \\
& \hat{P}(0)=\hat{Z}(0)=1
\end{aligned}
$$

Rather than work with $\hat{P}$ and $\hat{Z}$ directly, it is more convenient to use $\hat{P}$ and a new variable $x$, defined by:

$$
x \equiv(\hat{Z} \hat{P})^{-1 / 3}
$$

Then, dividing the first of eqs. (10) by the second:

$$
\begin{aligned}
& \frac{d \hat{P}}{d x}=\frac{3 \hat{P} x}{\alpha} \quad q-\frac{x^{3}}{x^{3}-1} \Delta(\hat{P}-1) \\
& \text { at } x=1 ; \hat{P}=1
\end{aligned}
$$

Once eq. (12) has been solved, the dimensionless time $\tau$ can be recovered by using the second of eqs. (10).

$$
\tau=\frac{3}{\alpha} \int_{1}^{\mathrm{x}} \mathrm{dss} \hat{\mathrm{P}}(\mathrm{s})
$$

Equation (13) also shows that the domain of interest for $\mathrm{x}$ is given by $1 \leq x \leq \infty$.

The infitial value problem defined by eq. (12) can be readily solved by noting that the equation, though non-linear, is of the Ricatti type. Thus, writing $\hat{P}(x)$ in the form

$$
\hat{P}(x)=f(x) \frac{d \phi}{d x} / \phi
$$




$$
f(x)=\frac{\alpha}{3 \Delta}\left(x^{3}-1\right) / x^{4}
$$

leads to the following linear differential equation for $\phi$

$$
\frac{d^{2} \phi}{d x^{2}}=\frac{3 x q}{\alpha}-\frac{f^{\prime}}{f}+\frac{37 d}{\alpha} \frac{x^{4}}{x^{3}-1} \frac{d \phi}{d x}
$$

This can be immediately integrated once to yield:

$$
\frac{d \phi}{d x}=[a / f(x)] \exp \left\{3 q x^{2} / 2 \alpha+\int_{1}^{x} d t / f(t)\right\}
$$

Integrating eq. (16) by parts then yields the general expression for $\phi$.

$$
\begin{aligned}
& \phi \equiv a\left\{\exp [u(x)]-\int_{1}^{x} d t(3 q t / \alpha) \exp [u(t)]+b\right\} \\
& u(x)=3 q x^{2} / 2 \alpha+\int_{1}^{x} d t / f(t)
\end{aligned}
$$

Using eqs. (16) and (17) in the recipe for $\hat{P}(x)$ given by eq. (14), and evaluating the constant $b$ from the initial condition given in eq. (12), the final expression for $\hat{P}(x)$ becomes:

$$
\begin{aligned}
& \frac{P}{P_{0}} \equiv \hat{P}(x)=1-\frac{3 q}{\alpha}[k(x)]^{-1} \int_{1}^{x} \operatorname{dssk}(s)^{-1} \\
& k(x)={\frac{x-1}{\sqrt{x^{2}+x+1}} \Delta / \alpha}^{\exp } 3(\Delta+q) x^{2} / 2 \alpha+\frac{\sqrt{3} \Delta}{\alpha} \arctan \frac{2 x+1}{\sqrt{3}}
\end{aligned}
$$

For convenience, the remainder of the solution can be summarized as a function of $\mathrm{x}$ as follows: 
$\hat{\mathrm{Z}} \equiv \frac{\mathrm{Z}}{\mathrm{H}}=\left[\hat{\mathrm{P}}(\mathrm{x}) \mathrm{x}^{3}\right]^{-1}$

$(\theta) \equiv \frac{T}{T_{0}}=1+x^{3}(\hat{P}-1) /\left(x^{3}-1\right)$

$\tau=\frac{3}{\alpha} \int_{1}^{x} d s s \hat{P}(s)$

Note that eqs. (18) and (19) constitute the exact solution to eqs. (10) for any values of the three parameters $\alpha, \Delta$, and $q$. Thus, if a somewhat different formulation of the model were adopted, with different physical constants of defining $\alpha, \Delta$, and $q$, eqs. (18) and (19) would st11l apply. Finally, the inftial value for the temperature can be extracted from this solution. Since small $\tau$ corresponds to $x$ near 1 ; from eq. (18) for $x-1 \ll 1$ :

$$
\hat{P}(x) \cong 1-3 q(x-1) /(\Delta+\alpha)
$$

Substituting this result into the second of eqs. (19); the desired result is obtained:

$$
\theta(0) \equiv \frac{T}{T_{0}}(0)=\frac{1+q}{\Delta+\alpha}
$$

\section{RESULTS AND DISCUSSION}

The above solution was applied to study the pressure and temperature rise induced by a 33.3 MW propellant fire in four compartments whose planform geometry is defined in table 1 . Each compartment was $3.05 \mathrm{~m}$ in height. 
Table 1

Summary of Magazine Planform Configurations

\section{Configuration}

1

2

3

4
Planform Dimensions (Meters)

$4.57 \times 4.57$
$9.15 \times 12.2$
$9.78 \times 14.6$
$12.2 \times 24.4$

The results are shown in figs. 1-4. Each figure consists of three parts, showing the time evolution for the first ten seconds of the interface height, pressure, and upper layer temperature in each compartment. Three curves are shown for each quantity, corresponding to differing estimates of the fraction $x$ of the chemical heat released lost to the boundaries by radiation. These curves should be treated as empirical calibration curves, to be used in conjunction with experimental data as it becomes available to determine the "best fit" value of $x$. For this purpose, the remaining physical parameters were held fixed at values given in table 2 .

\section{Table 2}

Summary of Reference Values for Physical Parameters Used in Figures $1-4$

Quantity

Pressure $P_{0}$ Temperature $\mathrm{T}_{0}$ Heat Transfer Coef. h Specific Heat Ratio $\gamma$ Gravitational Acceleration $g$
Value

1 Atm $=1.013 \times 10^{5} \mathrm{PA}$

$293 \mathrm{~K}$

$28.4 \mathrm{~W} / \mathrm{m}^{2} \mathrm{~K}$

1.4

$9.81 \mathrm{~m} / \mathrm{sec}^{2}$ 
The results indicate a substantial pressure rise in all cases, compared with the situation usually encountered in compartment fires. Indeed, only the heavily reinforced nature of the construction of the magazine permits such pressures to be achieved without rupturing the walls. In the case of configuration 1, it might not be possible to prevent rupture of the compartment walls if the upper end of the calculated range of pressures proves correct. Further work using the more detailed models listed in the references, but modified to account for hermetically or near hermetically sealed-type enclosures, is clearly needed. The present model can ultimately be most useful as a test case against which to check modified versions of the computer codes that implement the more general models.

\section{ACKNOWLEDGMENTS}

The author and his colleagues are grateful to Dr. Warren Jaul and Dr. Kent Farmer of the Navy Weapons Center for several discussions which provided a great deal of useful background information about the problem addressed in this report.

\section{REFERENCES}

[1] Cooper, L.Y. and Stroup, D.W. (1985). "ASET - A Computer Program for Calculating Available Safe Egresss Time", Fire Safety J. 9, p. 29.

[2] Mitler, H.E. (1985). "The Harvard Fire Model", Fire Safety J. 9, p. 7. 
[3] Jones, W.W. (1985). "Future Directions for Modeling the Spread of Fire, Smoke, and Toxic Gases", Fire Safety: Science and Engineering, ASTM STP 882, T.Z. Harmathy, Ed., American Society for Testing and Materials, Philadelphia, p. 70 .

[4] Quintiere, J. (1984). "A Perspective on Compartment Fire Growth", Combustion Science and Technology 39, p. 11.

[5] Cetegen, B.M., Zukoski, E.E. and Kubota, T。 (1984)。 "Entrainment in the Near and Far Field of Fire Plumes", Combustion Science and Technology 39 , p. 305 . 
$\mathrm{Z} / \mathrm{H}$

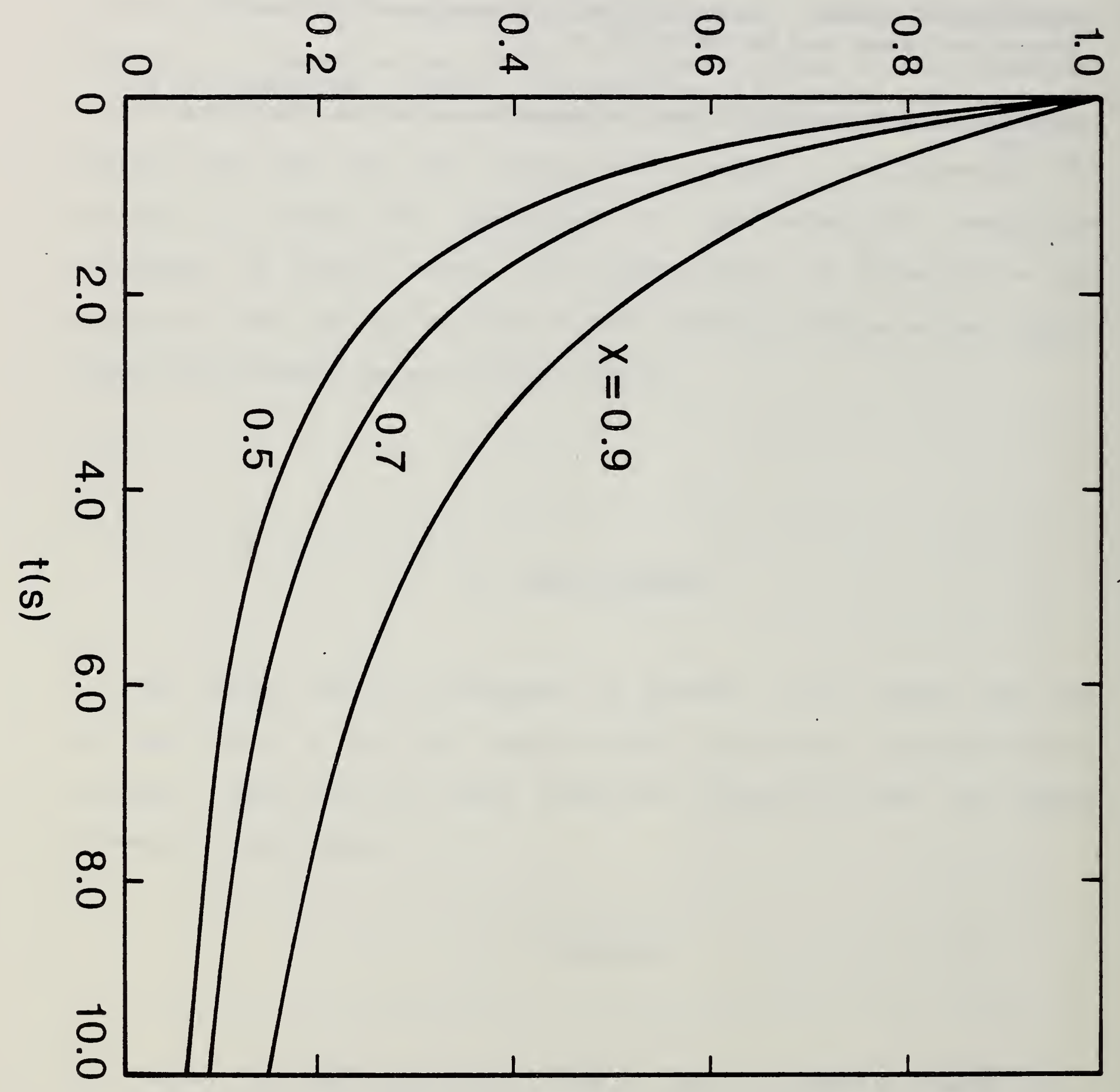

Figure la. Dimensionless layer height $\mathrm{Z} / \mathrm{H}$ as function of time in seconds for configuration 1. $X$ is the fraction of the chemical heat release lost from the gas by radiation. 


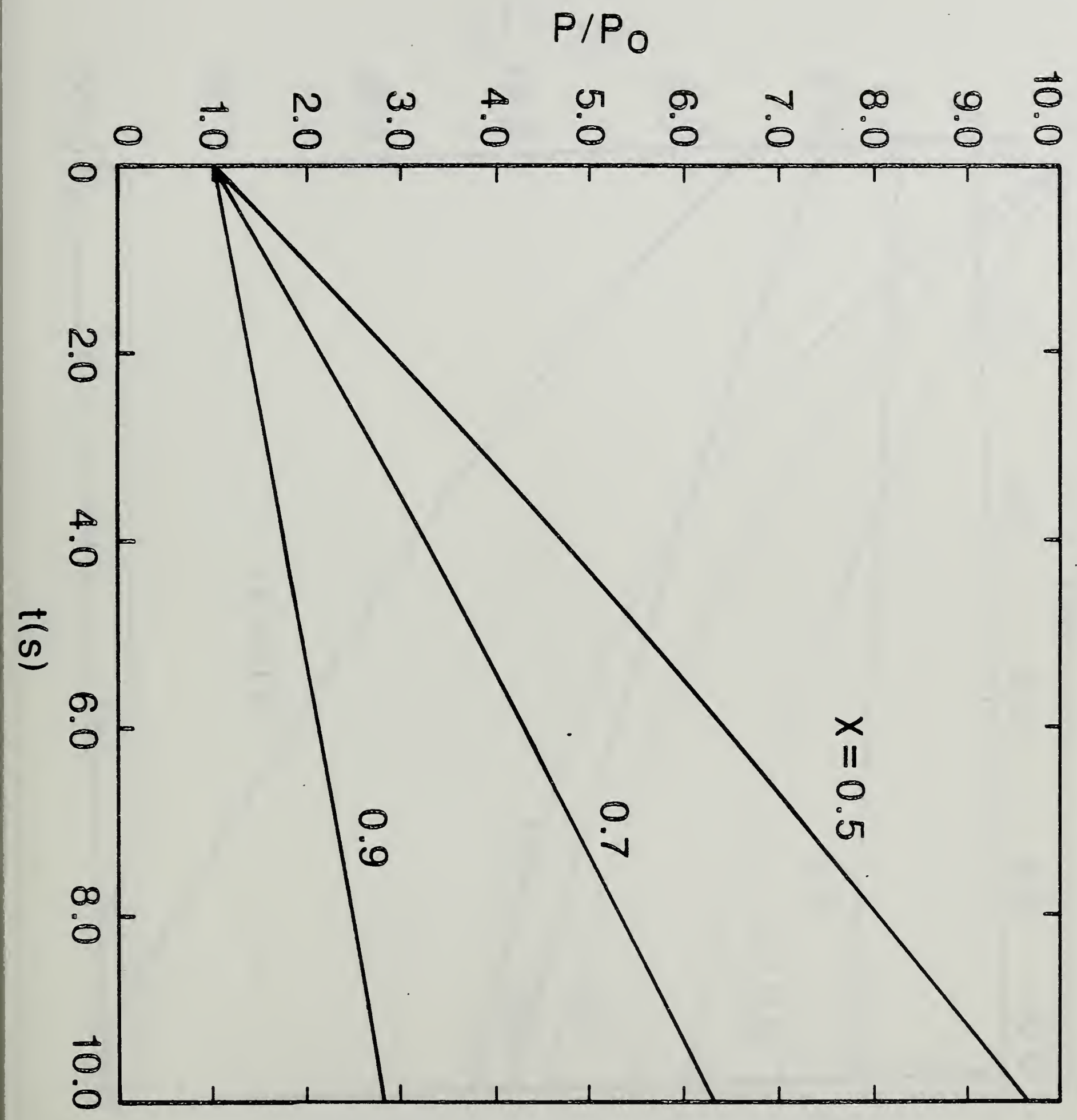

Figure 1b. Pressure in atmospheres as

function of time in. seconds for configuration 1 . 


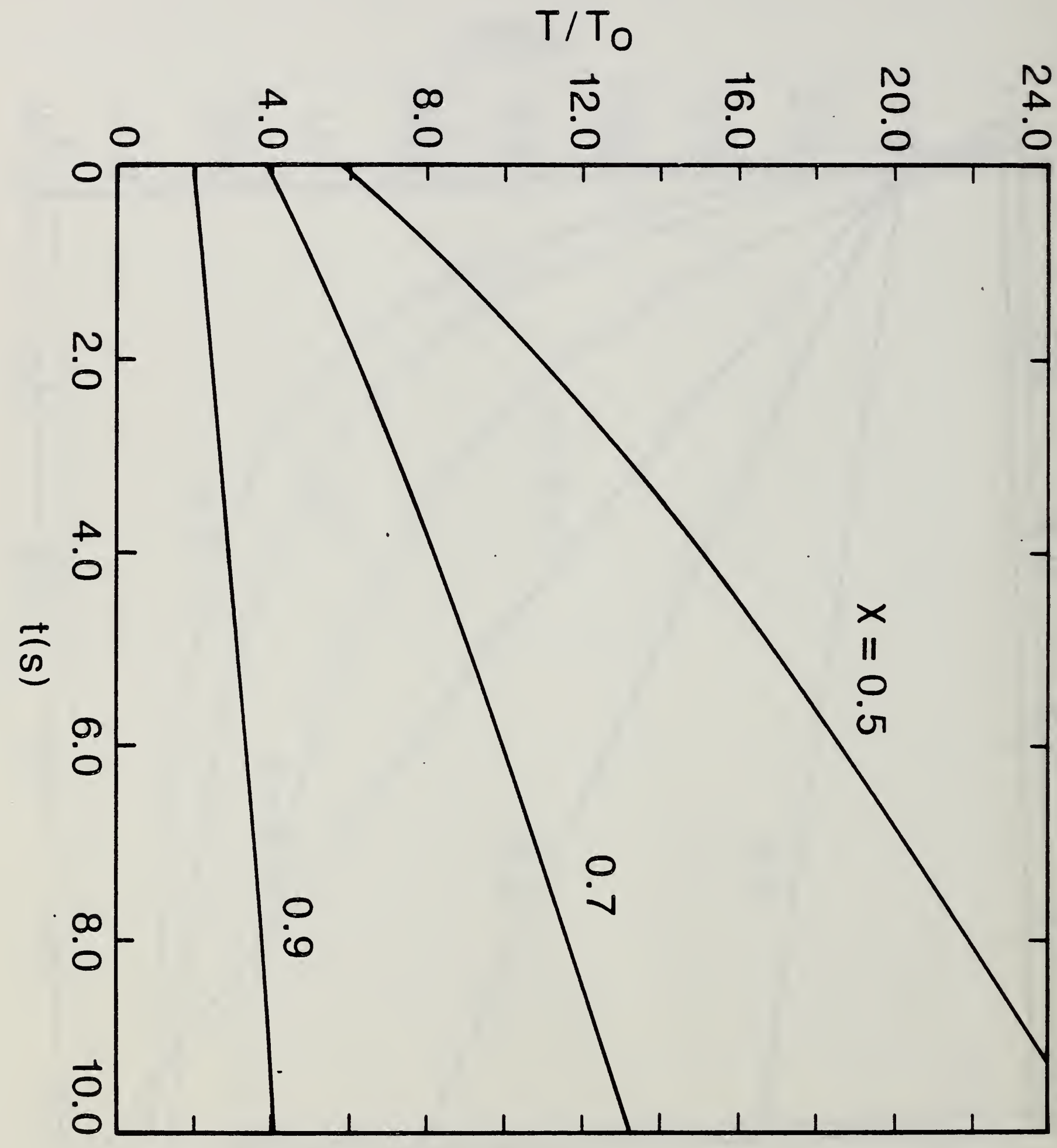

Figure 1c. Ratio of upper layer temperature to ambient temperature as function of time in seconds for configuration 1 . 


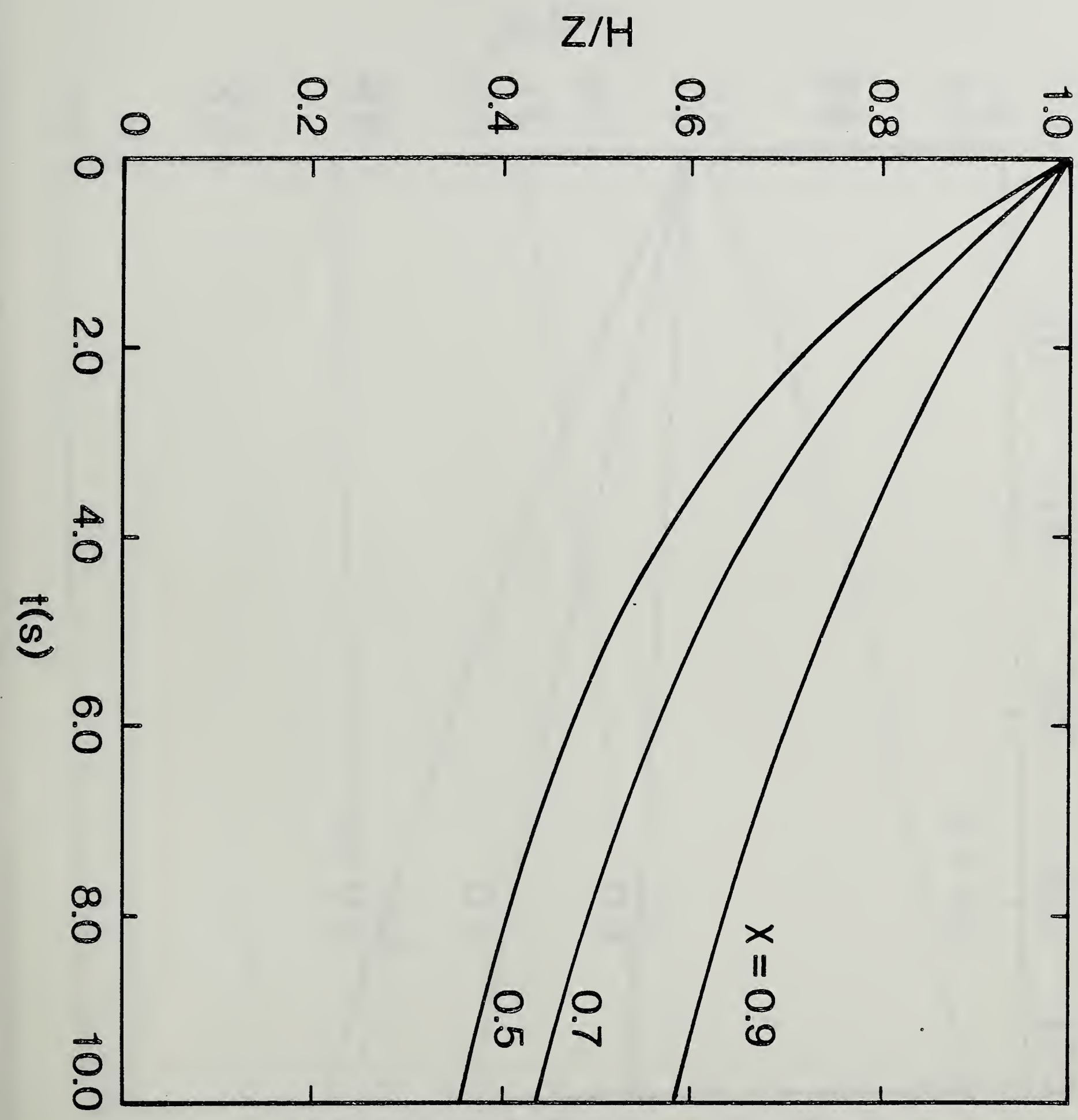

Figure 2a. Dimensionless layer height $\mathrm{Z} / \mathrm{H}$ as function of time in seconds for configuration 2. $X$ is the fraction of the chemical heat release lost from the gas by radiation. 


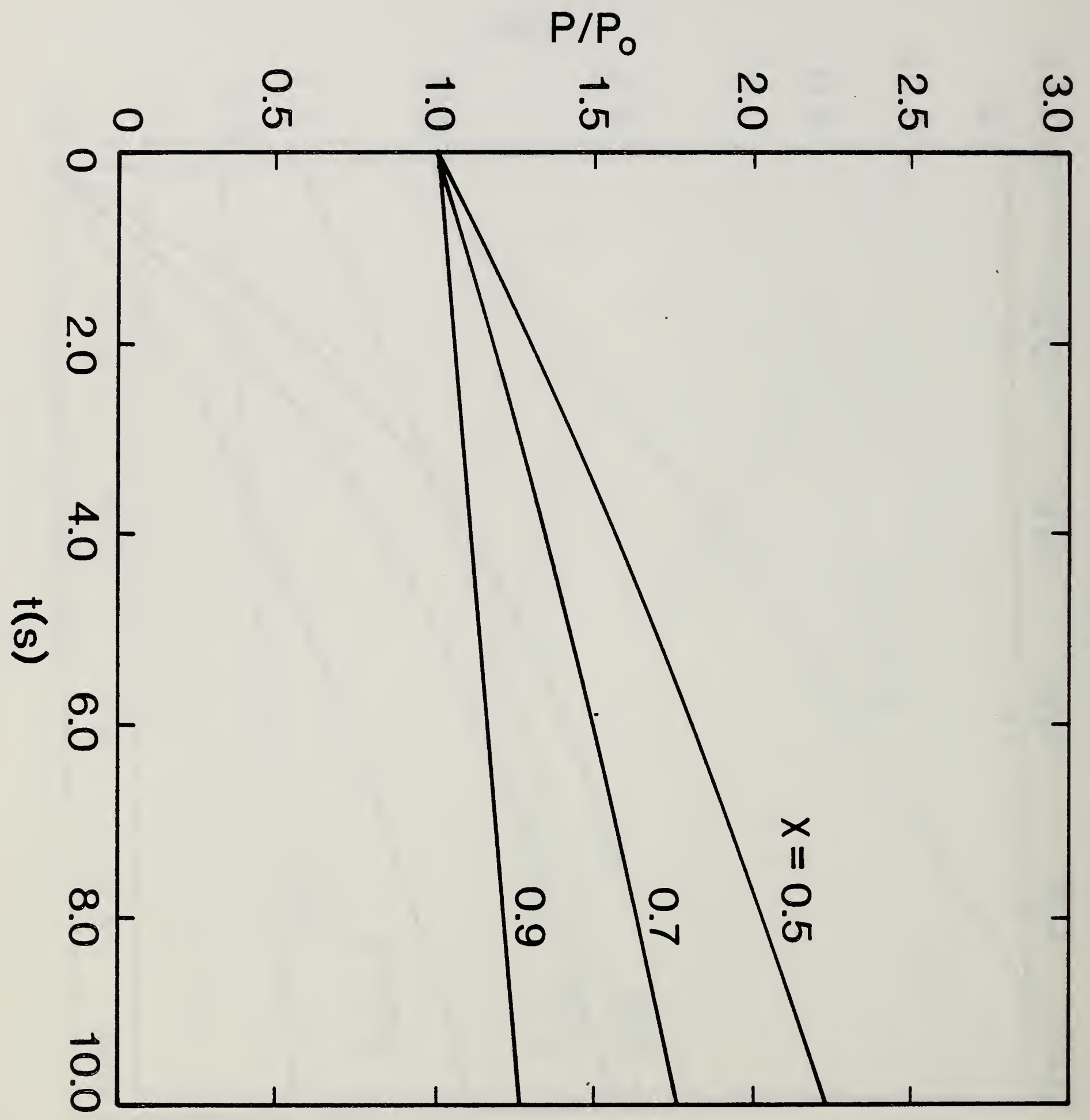

Figure 2b. Pressure in atmospheres as function of time in seconds for configuration 2. 


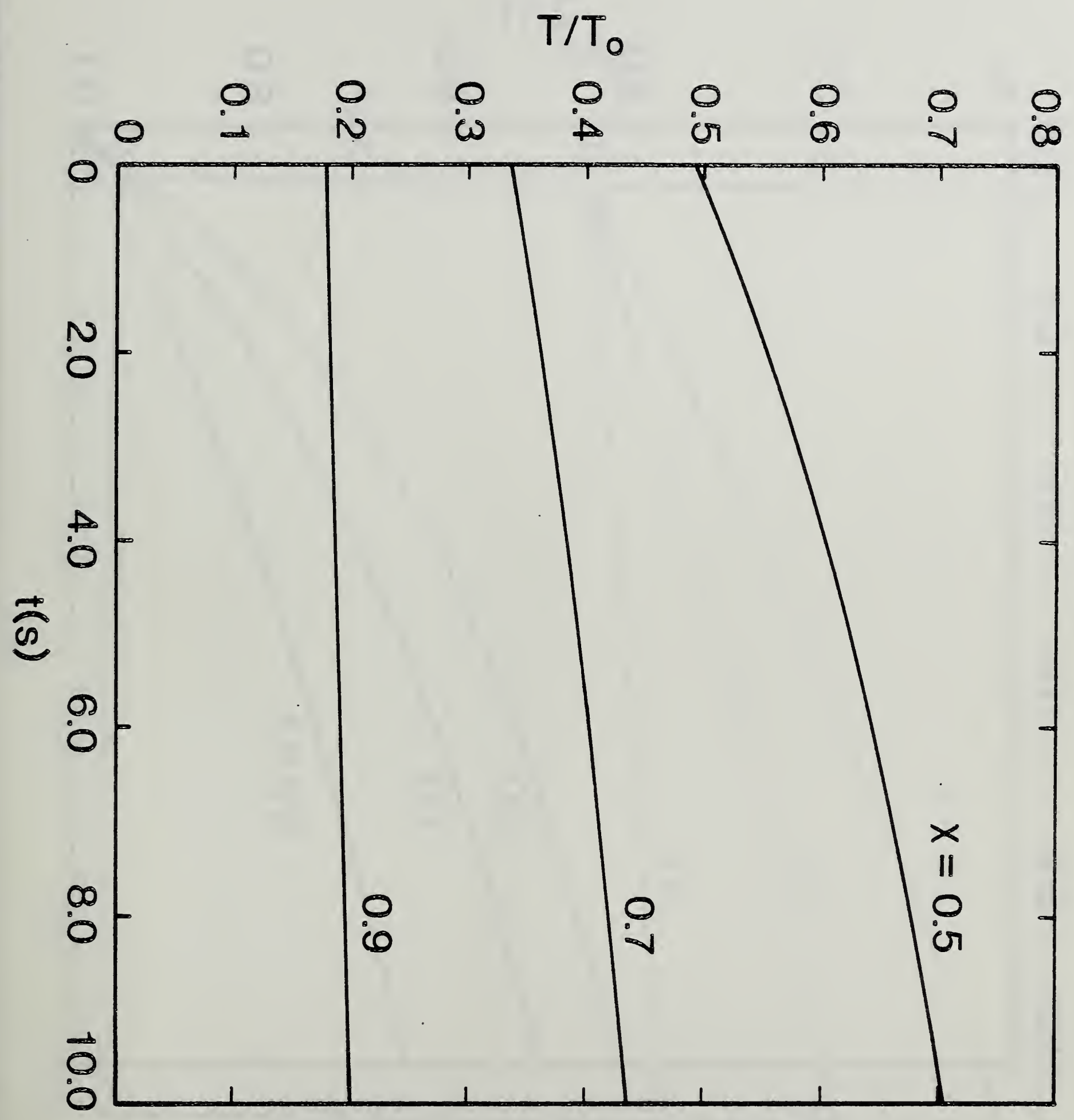

Figure 2c. Ratio of upper layer temperature

to ambient temperature as function of time in seconds for configuration 2 . 


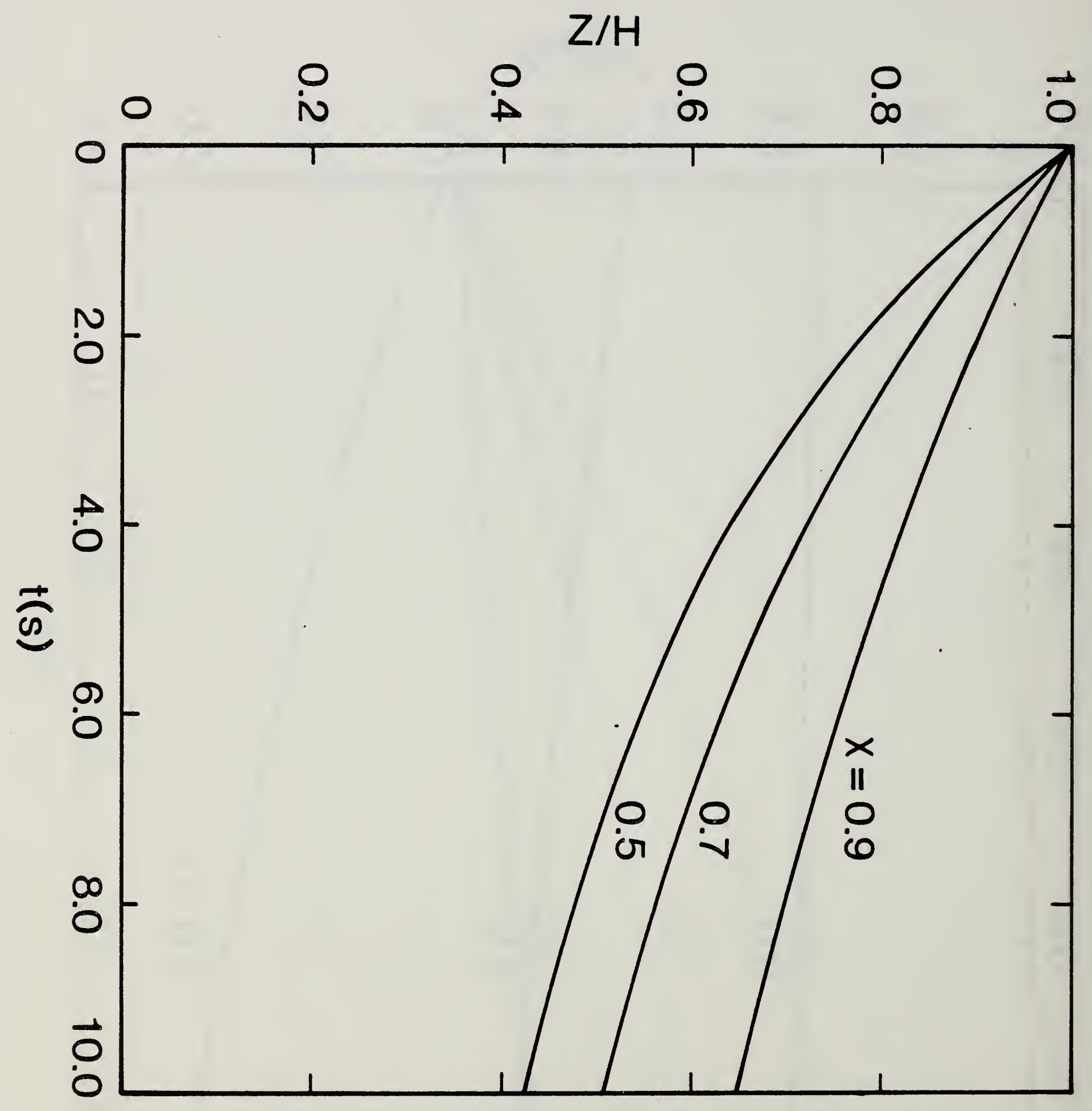

Figure 3a. Dimensionless layer height $\mathrm{Z} / \mathrm{H}$ as function of time in seconds for configuration 3. $X$ is the fraction of the chemical heat release lost from the gas by radiation. 


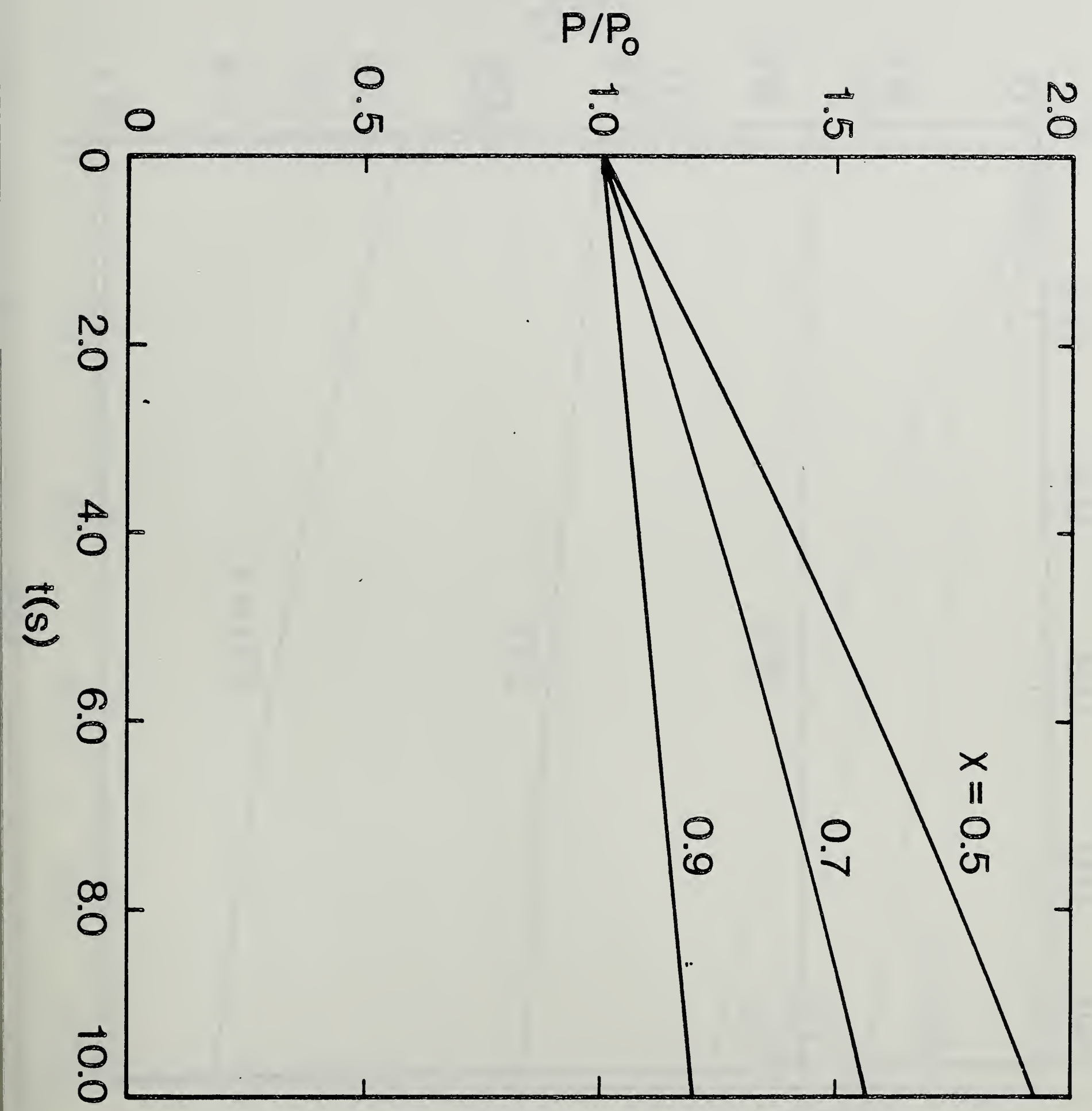

Figure 3b. Pressure in atmospheres as

function of time in seconds for configuration 3 . 


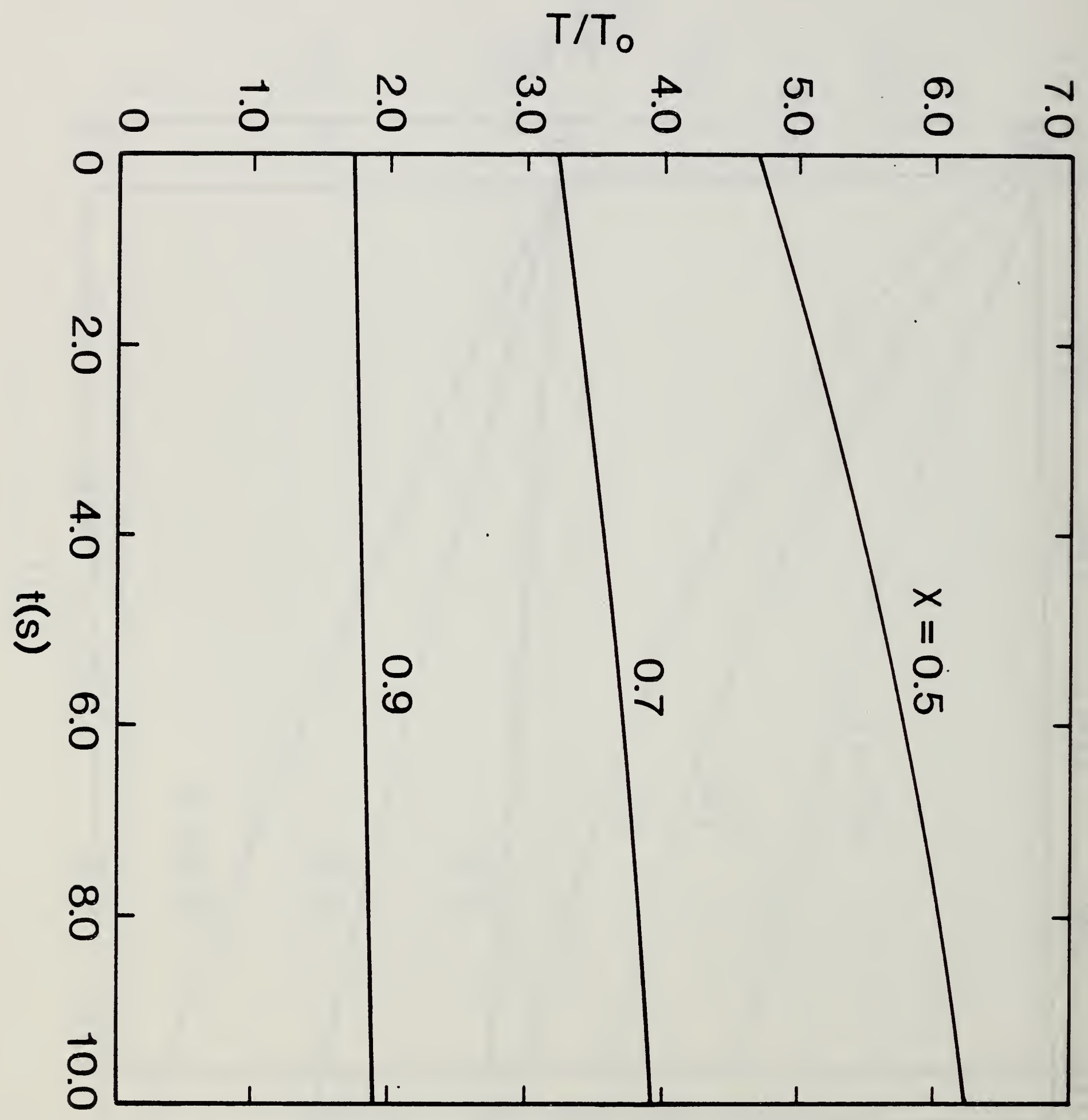

Figure 3c. Ratio of upper layer temperature to amblent temperature as function of time in seconds for configuration 3 . 
$\mathrm{Z} / \mathrm{H}$

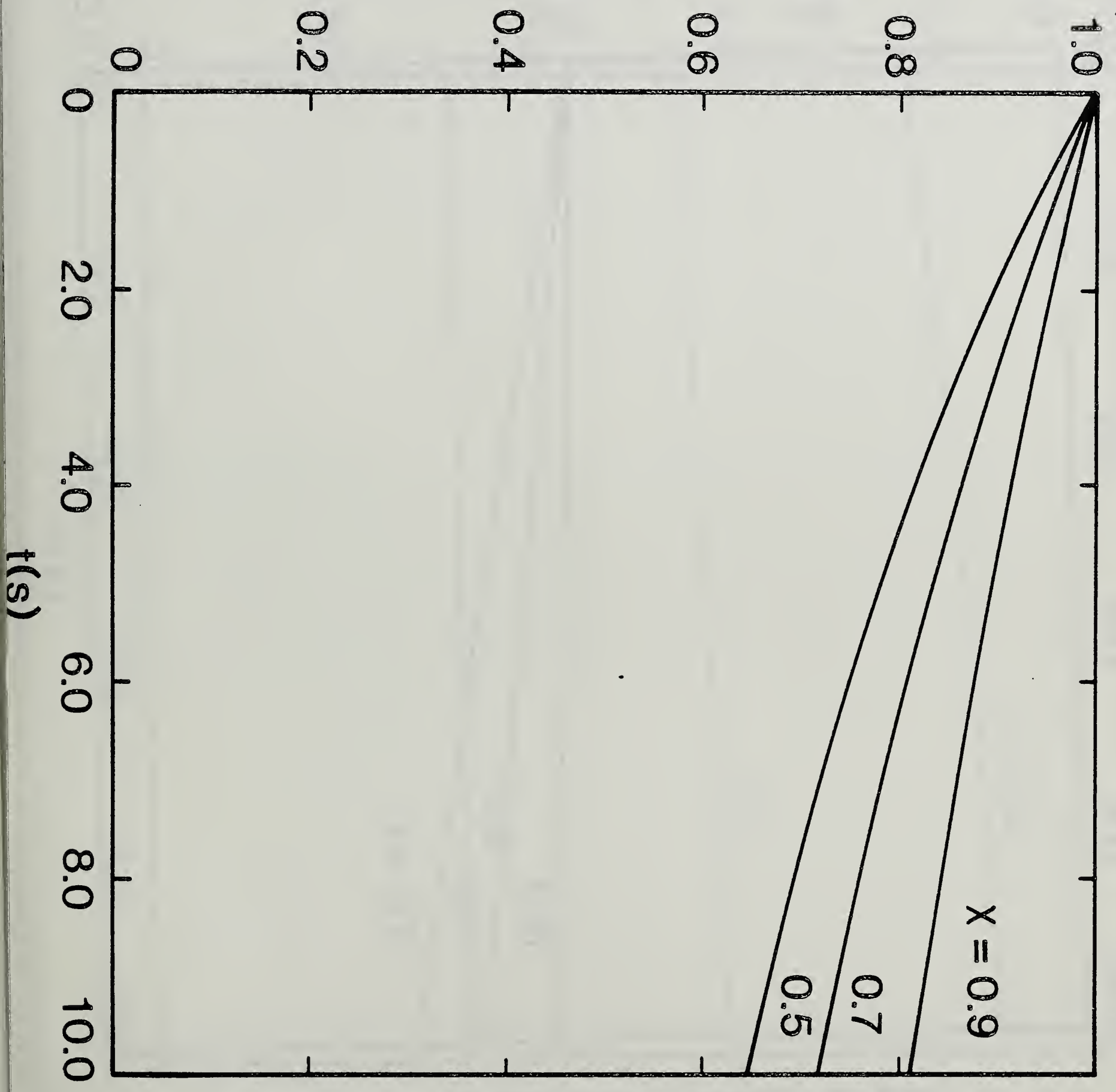

Figure 4a. Dimensionless layer height $\mathrm{Z} / \mathrm{H}$ as function of time in seconds for configuration 4. $X$ is the fraction of the chemical heat release lost from the gas by radiation. 


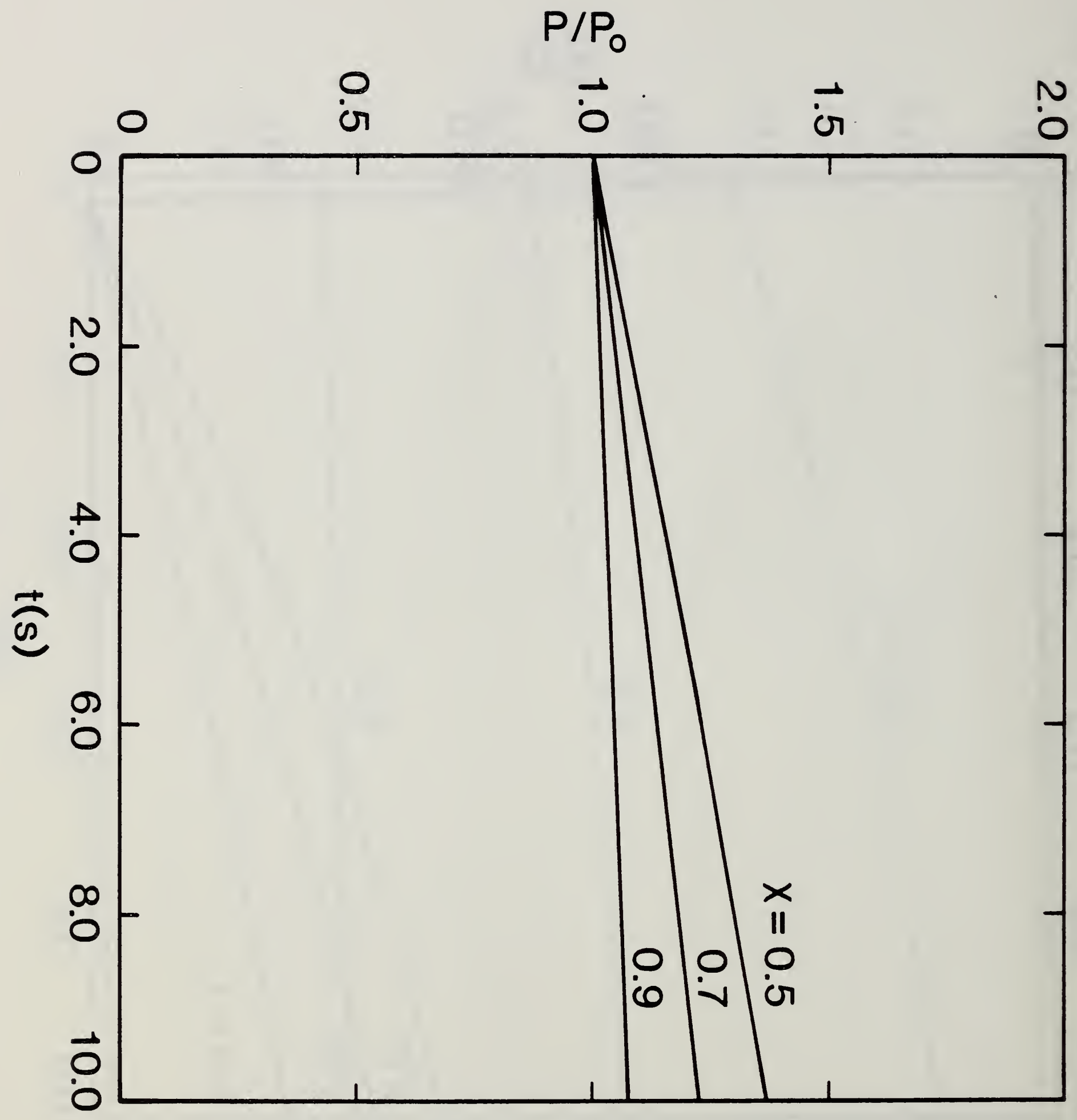

Figure 4b. Pressure in atmospheres as

function of time in seconds for configuration 4 . 


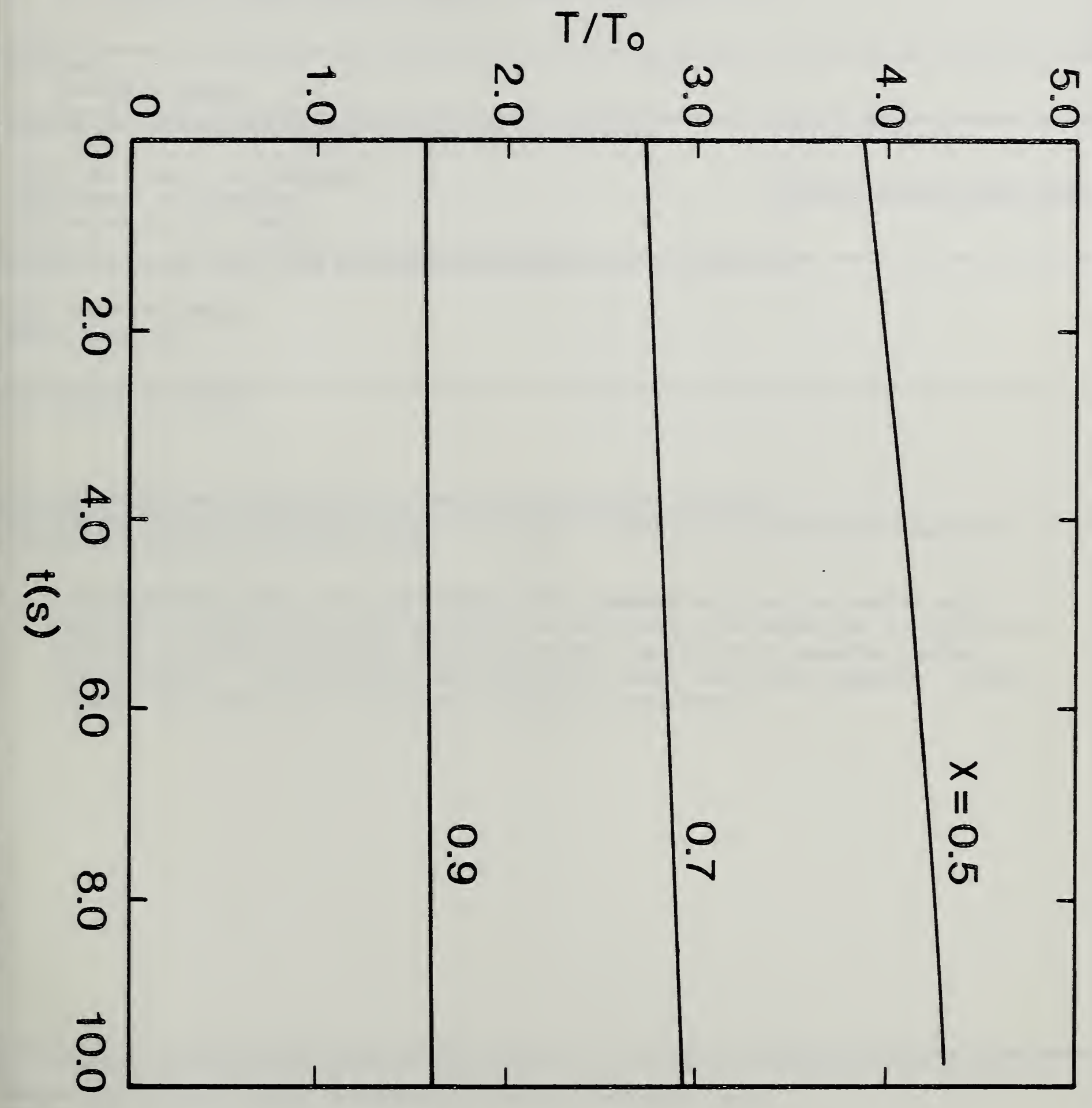

Figure 4c. Ratio of upper layer temperature to amblent temperature as function of time in seconds for configuration 4 . 
" 
MBS. IILA IREV. 2000$)$

U.S. DEPT. OF COMM.

1. PUBLICATION OR REPORT NO.

BIBLIOGRAPHIC DATA

SHEET (See instructions)

NBSIK-87/3557

2. Performing Organ. Report Nof 3. Publication Date

November 1987

4. TITLE AND SUBTITLE

An Analysis of the Pressure Rise in Sealed Magazine Fires

5. $A U T H O R(S)$

Howard R。 Baum

6. PERFORMING ORGANIZATION (If joint or other than NBS, see instructions)

7. Contrace/Grane No.

National Bureau of Standards

Department of Commerce

8. Type of Repore \& Perlod Covered

Gaithersburg, MD 20899

9. SPONSORING ORGANIZATION NAME AND COMPLETE ADDRESS (Stree? City. Stote, ZIP)

Navy Weapons Center

China Lake, CA

10. SUPPLEMENTARY NOTES

Document describes a computer program: SF-185. FIPS Sofeware Summary. is attached.

11. ABSTRACT (A 200-word or less foctual summan of most significant informotion. If document includes a significant bibliogrophy or literature survey. mention it here)

A mathematical model for the pressure and temperature ise in sealed ship magazines caused by propellant fires is developed. The model is a simplified version of several existing zone fire models, modified to consider sealed compartments. The equations describing the model are solved exactly. Sample results are shown for a varlety of magazlne geometrles.

12. KEY WORDS (Six to twelve entries: alphabetical order; capitalize only proper names; ond sepopate key words by semicolons) compartment fires; fires; mathematical models; pressure rise; : zone models

13. AVAILABILITY

[X] Unlimited

For Official Distribution. Do Not Release to NTIS

Order From Superintendent of Documents. U.S. Government Printing Office, Washington. D.C. 20402.

X] Order From National Technical Information Service (NTIS), Springfield. VA. 2216I

14. NO. OF

PRINTED PAGES

28

15. Price

$\$ 11.95$ 


